\title{
REALIZACIÓN DE UN DOSSIER COLABORATIVO SOBRE ESTIRAMIENTOS EN EL GRADO DE FISIOTERAPIA
}

\author{
Naia Entonado, Zeltia'; Bello Rodríguez, Olalla²; Ramos Gómez, Fernando³ \\ ${ }^{1}$ Universidade da Coruña, Facultade de Fisioterapia , id0000-0001-7878-4018 \\ ${ }^{2}$ Universidade da Coruña, Facultade de Fisioterapia , id0000-0002-7846-3123 \\ ${ }^{3}$ Universidade da Coruña, Facultade de Fisioterapia, id0000-0002-7829-9597
}

\section{RESUMO}

El movimiento, como agente físico aplicado con un fin terapéutico, es la base de la Cinesiterapia. Se constituye como un pilar fundamental dentro del curriculum del grado de Fisioterapia. Dentro de la asignatura "Cinesiterapia: bases del ejercicio terapéutico", se desarrolla el aprendizaje de distintas técnicas basadas en la utilización del movimiento, como agente terapéutico. Para abordar la docencia práctica de la materia, se realiza un dossier con imágenes de la ejecución de estiramientos neuromusculares, de forma colaborativa. Esta metodología docente facilita la motivación del alumnado y su participación en el desarrollo de materiales nuevos de aprendizaje, construidos de forma grupal.

PALABRAS CLAVE: Fisioterapia, cinesiterapia, estiramientos, dossier colaborativo

\section{CITA RECOMENDADA:}

Naia Entonado, Zeltia; Bello Rodríguez, Olalla; Ramos Gómez, Fernando (2021): Realización de un dossier colaborativo sobre estiramientos en el grado de Fisioterapia. En García Naya, J.A. (ed.) (2021). Contextos universitarios transformadores: a nova normalidade académica. Leccións aprendidas e retos de futuro. V Xornadas de Innovación Docente. Cufie. Universidade da Coruña. A Coruña (pág. 267-272). DOl capítulo: https://doi.org/10.17979/spudc.9788497498180.267

DOl libro: https://doi.org/10.17979/spudc. 9788497498180 


\section{ABSTRACT}

Movement, as a physical agent applied with a therapeutic goal, is the basis of Kinesiotherapy. It is a fundamental pillar of the curriculum of Physiotherapy degree program. Within the subject "Kinesiotherapy: basis of therapeutic exercise", the learning of different techniques based on the use of movement as a therapeutic agent is developed. In order to approach the practical training, the students and the university professors desing a collaborative dossier about execution of neuromuscular stretching techniques. This teaching methodology facilitates motivation and participation of the students in the development of new learning materials, built in group.

KEY WORDS: Physical therapy, kinesiotherapy, stretching, collaborative dossier 


\section{INTRODUCCIÓN}

La cinesiterapia se define como el uso del movimiento, un agente físico, con un fin terapéutico. Se constituye como un pilar fundamental dentro del curriculum del grado de Fisioterapia. El ejercicio terapéutico es la realización sistematizada y planificada de movimientos corporales, posturas y actividades que tienen por objetivo remediar o prevenir alteraciones, mejorar la función física, prevenir o reducir factores de riesgo relacionados con la salud, optimizar el estado de salud, la condición física o la sensación de bienestar ${ }^{1}$. Dentro de los contenidos de la asignatura "Cinesiterapia: bases del ejercicio terapéutico", se encuentra el desarrollo de las capacidades físicas básicas, y el diseño de programas de ejercicio terapéutico. Los estiramientos musculares se definen como la colocación en posición de elongación máxima de las estructuras músculoesqueléticas. Es una de las técnicas a desarrollar por parte de los estudiantes del grado de Fisioterapia, en la asignatura de Cinesiterapia.

\section{DESCRICIÓN DA EXPERIENCIA}

Se diseñó un dossier colaborativo en formato Power Point, donde se explica la ejecución de estiramientos en 24 grupos musculares. El objetivo de esta experiencia fue aumentar la participación y la implicación del alumnado en la adquisición de los contenidos de la materia. La ejecución técnica de los estiramientos músculoesqueléticos se desarrollan durante la docencia práctica. Ésta tiene lugar en grupos pequeños, de entre 8-14 personas. El profesorado realiza la ejecución práctica, y posteriormente el alumnado reproduce las técnicas. Se desarrolló un dossier colaborativo entre todo el alumnado. El profesorado, con permiso del alumnado, sacó fotografías de distintos momentos de la ejecución de los estiramientos: inicio, tomas, puesta en tensión, posición final. Todo el alumnado de la asignatura colaboró para poder desarrollar dicho dossier. El profesorado realizó la maquetación de las mismas, que incluyó una descripción de las pruebas y representación de los ventores de fuerza a ejecutar. En el dossier colaborativo, se editaron las caras del 
alumnado, de tal modo que ninguno pudiera ser reconocido. Al final de las prácticas, se compartió el documento con el alumnado en formato PDF.

En la Imagen 1 se observa un ejemplo de las imágenes empleadas y su resultado final.

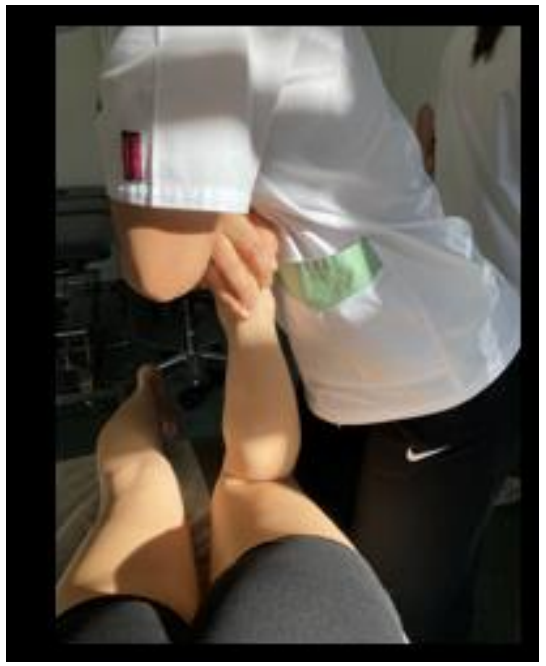

Imagen 1: fotografía de la posición final de un estiramiento

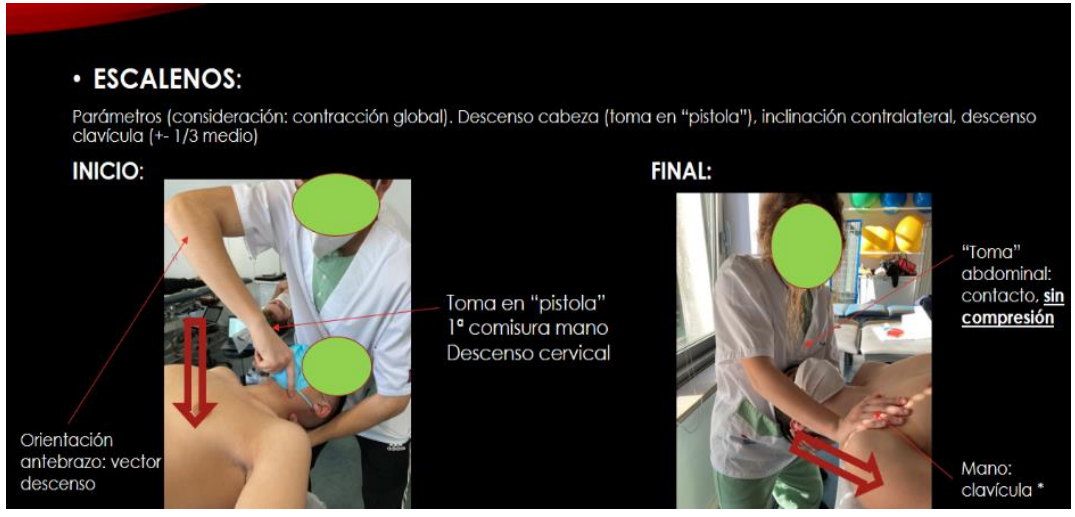

Imagen 2: fotografías maquetadas y editadas, con comentarios y representación de los ventores de fuerza. 


\section{RESULTADOS}

Para valorar la experiencia, se diseñó un cuestionario para identificar la opinión del alumnado sobre las experiencias de innovación docente realizadas en la materia. Se elaboró una pregunta sobre este dossier participativo, en la que se solicitaba al alumnado su grado de acuerdo 0 desacuerdo con la siguiente afirmación: "El documento de Estiramientos, realizado con las fotografías del alumnado, me ha ayudado en la comprensión de este tema". El alumnado debía valorar, en una escala numérica, su grado de acuerdo o desacuerdo; la puntuación 1 significaba "estoy completamente en desacuerdo", y la puntuación 7 "estoy completamente de acuerdo". En total, se obtuvieron 22 respuestas válidas.

2. El documento de "Estiramientos", realizado con las fotografías del alumnado, me ha ayudado en la comprensión de este tema.

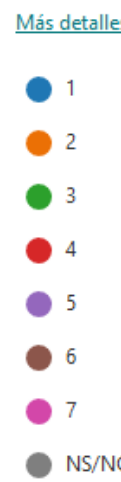

0
0
0
0
2
5
19
0

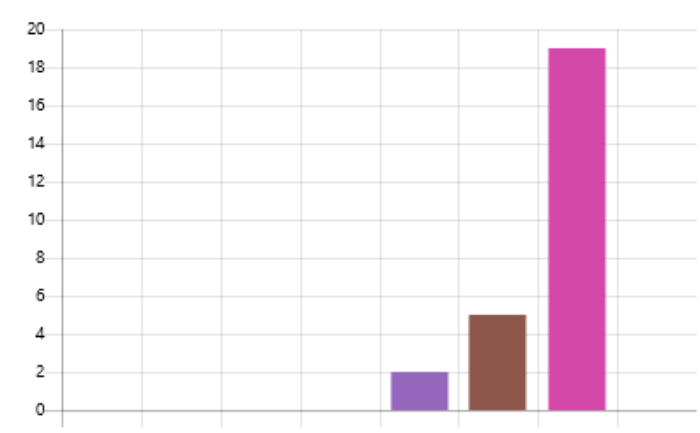

El valor media fue de 6,65, el valor más alto, 7 y el más bajo 5 .

\section{CONCLUSIONES}

El alumnado manifestó que el dossier colaborativo le resultó útil en la adquisición de los contenidos de la material. Además, el profesorado percibió un aumento de la participación e interacción del alumnado en un trabajo colaborativo, durante la docencia práctica. De cara a futuras experiencias, se podría permitir que también colaborasen en la maquetación y edición del dossier. 


\section{BIBLIOGRAFÍA:}

Walker B. (2011). Anatomía y Estiramientos. Guía de estiramientos y descripción anatómica. Badalona, Paidotribo.

Johnson J. (2013): 140 estiramientos terapéuticos. Madrid, Tutor.

Nelson AG, Kokkonen J. (2014):Anatomía de los estiramientos. Madrid, Tutor.

Geoffroy Ch. (2011): Guía práctica de los estiramientos. Badalona, Paidotribo.

Neiger H, Gosselin P. (1998): Estiramientos analíticos manuales. Madrid, Panamericana.

Esnault, Michèle (1994): Estiramientos analíticos en fisioterapia activa. Barcelona : Masson.

Esnault, Michèle(2009): Columna vertebral y stretching. Badalona : Paidotribo.

Ylinen, J. (2009): Estiramientos terapéuticos en el deporte y en las terapias manuales. Barcelona: Churchill Livingstone. 